\title{
A (R)EVOLUÇÃO DA EDUCAÇÃO 4.0 NO ENSINO DE CIÊNCIAS E MATEMÁTICA EM ESCOLAS DA REDE ESTADUAL DA PARAÍBA.
}

\author{
Priscila da Silva Santos - IFPB - priscilasilva.fis@gmail.com \\ Priscila de Souza Maciel - IFPB - priscila.maciel@ifpb.edu.br
}

\begin{abstract}
RESUMO
A quarta Revolução Industrial (Indústria 4.0) trouxe consigo grandes mudanças em diversos segmentos da sociedade. Surge então a necessidade de profissionais com novas competências e habilidades exigidas para este novo cenário em que a linguagem computacional, a Internet das Coisas, a Inteligência Artificial, os robôs e muitas outras tecnologias estão cada vez mais presentes. Para acompanhar essa evolução tecnológica surge a Educação 4.0, que consiste em um conjunto de recursos tecnológicos utilizados de maneira integrada, a partir da inteligência artificial, robótica, telecomunicação, entre outras. Diante do exposto surge a necessidade de analisar como os docentes estão acompanhando esse processo de evolução tecnológica e como as Tecnologias Digitais da Comunicação e Informação podem colaborar diante desse novo contexto. Dessa forma, esta pesquisa tem por objetivo compreender como a prática docente de profissionais de ciências da natureza e matemática da rede estadual da Paraíba tem acompanhado essa (r)evolução tecnológica. A pesquisa é caracterizada como um estudo de caso e, apresenta como os professores tiveram que se (re)inventar sob a perspectiva da inovação e tecnologia, devido o atual Regime Especial de Ensino na Paraíba, em decorrência da pandemia da COVID-19.
\end{abstract}

PALAVRAS-CHAVE: Educação 4.0; Docência; Ciências; Matemática.

\section{THE (R) EVOLUTION OF EDUCATION 4.0 IN SCIENCE AND MATHEMATICS TEACHING IN SCHOOLS IN THE STATE OF PARAÍBA.}

\begin{abstract}
The fourth Industrial Revolution (Industry 4.0) brought with it great changes in different segments of society. Then there is a need for professionals with new competencies and skills required for this new scenario in which computational language, the Internet of Things, Artificial Intelligence, robots and many other technologies are increasingly present. To accompany this technological evolution, Education 4.0 appears, which consists of a set of technological resources used in an integrated manner, from artificial intelligence, robotics, telecommunication, among others. Given the above, there is a need to analyze how teachers are following this technological evolution process and how Digital Technologies of Communication and Information can collaborate in the face of this new context. Thus, this research aims to understand how the teaching practice of professionals in natural sciences and mathematics from the Paraíba state network has accompanied this (r) technological evolution. The research is characterized as a case study and presents how teachers had to (re) invent themselves from the perspective of innovation and technology, due to the current Special Teaching Regime in Paraíba, due to the pandemic of COVID-19.
\end{abstract}

KEYWORDS: Education 4.0, Teaching, Science, Mathematics. 


\section{Introdução}

A quarta Revolução Industrial (Indústria 4.0) trouxe consigo grandes mudanças, não apenas na Indústria, mas em diversos segmentos da sociedade. Com a Indústria 4.0, surge a necessidade de profissionais com novas competências e habilidades exigidas para este novo cenário em que a linguagem computacional, a Internet das Coisas, a Inteligência Artificial, os robôs e muitas outras tecnologias se somam para dinamizar os processos nos mais diversos segmentos. Para acompanhar esse avanço tecnológico surge a Educação 4.0 que consiste em um conjunto de recursos tecnológicos utilizados de maneira integrada, a partir da inteligência artificial, robótica, telecomunicação, entre outras (CARVALHO et al.,2018). As Tecnologias Digitais da Informação e Comunicação (TDICs) são recursos, que se utilizados de forma acertada, são um grande aliado no processo de ensino e aprendizagem, nos quais alunos e professores podem criar, reproduzir, pensar e manipular a informação, proporcionando interatividade na construção do conhecimento.

Para Damasceno (2019) o professor age como coautor no processo de ensino e aprendizagem, enquanto os alunos são autores do próprio conhecimento. Cabe assim ao professor promover e incentivar os estudantes pela busca de informações e conhecimento, favorecendo um aprendizado significativo. Segundo Reis (2017) a importância da utilização das TDICs no ensino de ciências e matemática é pauta de diversos estudos nas últimas décadas. Essa necessidade é observada pois as TDICs têm se mostrado como um instrumento que pode facilitar a compreensão dos conceitos na área de ensino de ciências e matemática, tornando-os menos abstratos, mais práticos e compreensíveis do que são considerados pelos estudantes.

Este trabalho busca analisar como a prática docente de profissionais de ciências da natureza e matemática da rede estadual da Paraíba tem acompanhado a (r)evolução tecnológica dentro do contexto da Educação 4.0. Esta pesquisa é de natureza aplicada, quanto ao objetivo classifica-se como descritiva e de acordo com o procedimento, denomina-se um estudo de caso. A coleta de dados deu-se através de formulário do Google Forms, o qual foi divulgado e enviado para professores de todo o Estado da Paraíba, através de aplicativo de conversas e e-mails institucionais de todos os professores do estado. Observa-se que os professores tiveram que reinventar suas práticas diante do Regime Especial de Ensino adotado pelo Governo do Estado da Paraíba em decorrência da pandemia da COVID-19. Em virtude de tais circunstâncias o processo de ensino e aprendizagem, não apenas em ciências e matemática, mas em todas as áreas do conhecimento sofreram uma forte influência da inovação e tecnologia.

\section{A educação 4.0 e a utilização de TDICs no ensino de ciências e matemática}

Vivenciamos um processo de constante evolução e desenvolvimento nos mais diversos setores como a indústria, a saúde, a economia, assim como na educação. As descobertas científicas e tecnológicas vão modificando nossa relação com o mundo, nossa percepção da realidade, nossa forma de pensar, de sentir, de interagir com os outros e até no nosso comportamento. A sociedade atual está cada vez mais conectada à tecnologia e a educação necessita acompanhar essa evolução.

A evolução tecnológica decorre principalmente de quatro períodos: as quatro revoluções industriais. A quarta revolução industrial, comumente chamada de Industria 4.0, teve seu início na Alemanha em 2011, e tem confluência com toda a tecnologia utilizada atualmente. A linguagem computacional, a Internet das Coisas, a Inteligência Artificial, os robôs e muitas outras tecnologias se somam para dinamizar os processos nos mais diversos segmentos da Indústria (Teles, 2017). De acordo com Führ (2018), a 
Revolução 4.0 resulta na transformação em três eixos: Categoria Física (veículos autônomos, impressão 3D, robótica avançada e novos materiais), Categoria Digital e Categoria Biológica.

De acordo com Teles (2017) a Industria 4.0 tem acelerado o mundo em diversas perspectivas, não apenas aqueles que estão diretamente ligados ao setor industrial, como erroneamente pode-se pensar. As modificações que aconteceram ao longo dos tempos, impulsionadas, principalmente pelas revoluções industriais, também perpassa pelas transformações nos modelos de gestão, pelas inovações tecnológicas, pela economia e pela globalização, acarretando constantes mudanças na formação acadêmica e profissional. Produzir num ambiente 4.0 exige mudanças no que diz respeito à organização do trabalho. Portanto, um grande desafio é capacitar as pessoas, formar profissionais com as competências exigidas para este novo cenário. Diante disto, surge uma nova demanda, de uma educação que responda às necessidades da "Indústria 4.0" (Melo \& Oliveira, 2019), que de acordo com Carvalho Neto $(2018$, p. 2) "consiste em uma abordagem teórico-prática avançada para a gestão e docência na educação formal que vem demonstrando, por evidência de pesquisas de base científica e tecnológica, seu potencial transformador e inovador para as instituições de ensino."

De acordo com Führ (2018, p. 98) "as contínuas e rápidas mudanças da sociedade contemporânea apresentam a exigência de um novo perfil docente". Diante disso, surge um grande desafio para os profissionais da educação, os quais necessitam acompanhar essa rápida evolução tecnológica. Para isso há uma grande necessidade de repensar a formação de professores para cumprir com as novas demandas dispostas nesse novo cenário.

Há décadas tem se discutido sobre a utilização das Tecnologias digitais da Informação e Comunicação (TDICs) na Educação. Nesse sentido, a Base Nacional Comum Curricular (BNCC) contempla o desenvolvimento de competências e habilidades relacionadas ao uso crítico e responsável das tecnologias digitais tanto de forma transversal, quanto de forma direcionada:

\footnotetext{
Compreender, utilizar e criar tecnologias digitais de informação e comunicação de forma crítica, significativa, reflexiva e ética nas diversas práticas sociais (incluindo as escolares) para se comunicar, acessar e disseminar informações, produzir conhecimentos, resolver problemas e exercer protagonismo e autoria na vida pessoal e coletiva. (BNCC, 2018, p. 9)
}

Segundo Macêdo et al. (2014) as Tecnologias de Informação e Comunicação são uma expressão geral que designa todos os meios técnicos usados para tratar a informação e facilitar a comunicação, incluindo hardware e software. Nesse sentido, o professor deixa de ser o responsável por apenas repassar conhecimento e começa a assumir o papel de orientador e incentivador. Torna-se essencial desenvolver estudantes com a habilidade de aprendizagem autônoma, capazes de acompanhar as inovações tecnológicas que avançam com uma velocidade cada vez maior. Para isso, o ambiente escolar também deve se adaptar a Educação 4.0 dando condições para a interação e a experimentação.

A Educação 4.0 é baseada primordialmente em metodologias ativas, tais como: STEAM (Science, Technology, Engineering, Art and Mathematics), a cultura Maker, o ensino híbrido, a aprendizagem baseada em projetos. A base para esse processo são as TDICs, que consistem em um conjunto de recursos tecnológicos utilizados de maneira integrada, a partir da inteligência artificial, robótica, telecomunicação, entre outras. Para que isso seja possível na educação, as tecnologias precisam ser utilizadas como ferramentas pedagógicas inovadoras que transformem as práticas educativas para facilitar o ensino com os recursos oferecidos. Os jovens estudantes já têm a tecnologia integrada 
à sua vida cotidiana e esperam isso também da escola. Carvalho et al. (2018) destaca a importância de a educação acompanhar "o mundo 4.0".

De acordo com Carvalho et al. (2018) as metodologias ativas são parte importante da educação 4.0 que tem como um dos principais pontos o "Learning by Doing", ou seja, o "aprender fazendo", geralmente realizado através de experiências e projetos com a unificação dos métodos dedutivos e indutivos de aprendizagem em que as tecnologias são amplamente exploradas como facilitadoras do processo.

Giasse e Ramos (2016) complementa que as TDICs transformam não só a maneira de se comunicar, mas também, de estudar, trabalhar, decidir e de pensar e que as escolas não podem ignorar isso. Santos (2007) acrescenta entre os benefícios do uso das TDICs, o fato de tornar o ensino das ciências mais interessante; propicia mais observação, discussão e análise e ainda maior possibilidade de criar situações de comunicação e colaboração. Para os autores, as mídias apresentam grande poder pedagógico, já que se utilizam da imagem e essas são essenciais, especialmente nas aulas de ciências cuja abstração nem sempre é bem captada por todos.

Loureiro (2019) disserta sobre o ensino de Física, mas podemos expandir sua fala para o ensino de ciências da natureza, e este constitui-se por uma busca em desenvolver no aluno o senso de curiosidade através do estudo de fenômenos presentes no dia a dia. Ensinar ciências vai além de transmitir os conteúdos curriculares já estabelecidos, por aulas arraigadas no modelo tradicional de ensino. Battisti (2016), afirma que as inúmeras tecnologias disponíveis geram possibilidades variadas no ensino de matemática.

Diante do exposto acima, devemos ainda contrapor os desafios que o professor enfrenta, já que o docente passa a ser encarregado de uma grande responsabilidade - a de utilizar as TDICs. Segundo Schuhmacher (2017), em publicações brasileiras são recorrentes relatos nos quais a maior dificuldade enfrentada pelos professores é a infraestrutura física da escola em termos de equipamentos, conexão de internet e ambientes em que esses equipamentos estão dispostos para utilização na prática do professor. A inexistência ou insuficiência de apoio institucional torna-se um agravante para o professor que busca adotar as TDICs em suas práticas. É importante enfatizar que o uso das TDICs não são a solução para uma educação de qualidade, no entanto, se bem utilizada com objetivos definidos acertadamente, associando-as a outros recursos didáticos, beneficia o processo de ensino aprendizagem, como elemento motivador da busca pelo conhecimento (Loureiro, 2019).

\section{Material e métodos}

A metodologia utilizada é de natureza aplicada, quanto ao objetivo classifica-se como descritiva e de acordo com o procedimento, denomina-se um estudo de caso (Prodanov, 2013). A coleta de dados escolhida para esse estudo de caso, foi o questionário on-line. De acordo com Moysés e Moori (2011) o questionário é um instrumento desenvolvido cientificamente, composto de um conjunto de perguntas ordenadas, que deve ser respondido sem a presença do entrevistador e que tem por objetivo coletar dados de um grupo de respondentes.

O questionário de coleta de dados foi enviado para todos os professores da rede estadual através do aplicativo WhatsApp e também para o e-mail institucional de cada professor em virtude da atual situação de pandemia. No e-mail e no aplicativo, conteve uma breve descrição do contexto da pesquisa e a solicitação de que apenas os professores de ciências da natureza e matemática respondessem ao questionário.

Para Moysés e Moori (2011) o questionário deve ser limitado em sua extensão e em sua finalidade, pois um questionário muito longo causa cansaço e desinteresse e um 
questionário muito curto pode não oferecer informações suficientes. Dessa forma o questionário conteve vinte e três perguntas objetivas, para favorecer a tabulação e análise das respostas, bem como garantir uma maior participação de entrevistados. Responderam à pesquisa 231 (duzentos e trinta e um) docentes da área de estudo, entre os dias 01e 10 de outubro de 2020. As perguntas buscaram traçar o perfil de cada profissional, bem como identificar seu conhecimento a respeito da educação 4.0 e uso das TDICs no processo de ensino e aprendizagem em Ciências da Natureza e Matemática. Foi possível também investigar o uso das TDICs no período que antecedeu a pandemia e o uso das mesmas, durante o chamado ensino remoto, o qual os professores estão vivenciando.

\section{Resultados e discussão}

O estado da Paraíba em termos de Educação, é dividido em quatorze Gerências Regionais de Ensino. Os professores respondentes a essa pesquisa, são majoritariamente da $1^{\mathrm{a}}, 2^{\mathrm{a}}, 3^{\mathrm{a}}$ e $4^{\mathrm{a}}$ Região de Ensino, totalizando $67 \%$ dos questionários respondidos, os demais (33\%) dividem-se entre as outras dez Gerências de Ensino.

De acordo com a Figura 1, a maioria dos professores participantes da pesquisa são jovens, resultando em tempo menor em sala de aula. Dos entrevistados, $74 \%$ tem até 40 anos e $56 \%$ do total de entrevistados são professores há 10 anos ou menos. Dos professores dentro da faixa etária até 40 anos, $90 \%$ estão elencados dentro dos que tem até 10 anos de profissão, sendo que 52\% destes, lecionam há 5 anos ou menos.

\section{Faixa etária}

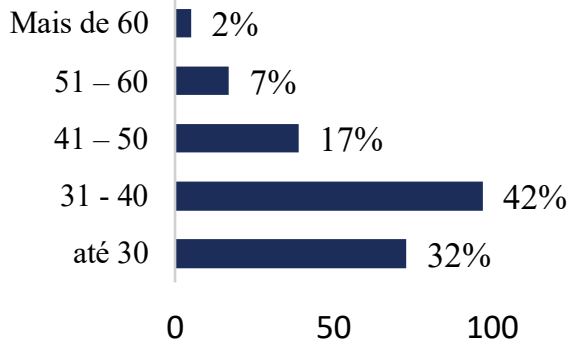

Tempo de profissão

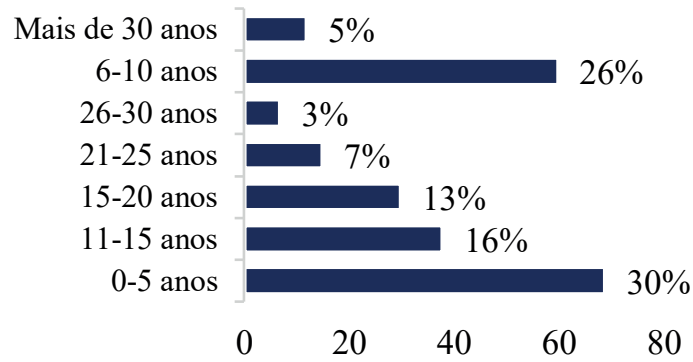

Figura 1 - Faixa etária e tempo em sala de aula dos professores entrevistados.

De acordo com o censo escolar 2019, do Instituto Nacional de Estudos e Pesquisas Educacionais Anísio Teixeira (INEP), 64,3\% dos professores do ensino médio regular da rede Estadual da Paraíba possui formação superior de licenciatura (ou bacharelado com complementação pedagógica) na mesma área da disciplina que leciona, caindo esse percentual para 58,1\% quando se trata da Educação para Jovens e Adultos (EJA); docentes com formação superior de licenciatura (ou bacharelado com complementação pedagógica) em área diferente daquela que leciona totalizam $22,3 \%$ no ensino médio regular, subindo para 29,6\% na EJA (INEP, 2019). Através do questionário aplicado, obteve-se que $86,6 \%$ dos docentes, lecionam a disciplina de sua área de formação, sendo que a maior parte dos que lecionam disciplina diferente de sua área de formação se encontra na EJA com $31,4 \%$ do total de professores; no ensino médio regular esse percentual cai para 5,6\%, o que corrobora com os dados do INEP.

Caracterizados os docentes entrevistados, as perguntas seguiram de acordo com o objeto de estudo desta pesquisa. Diante do atual contexto de Regime Especial de Ensino (REE) implementado na Paraíba, de acordo com a resolução 120/2020, em virtude da pandemia do COVID-19, faz-se necessário entender como esse contexto tem influenciado na evolução da utilização das TDICs e consequentemente, na evolução da Educação 4.0 
na Paraíba. Assim, algumas perguntas foram direcionadas para entender o período que antecede o REE.

Grande parte dos docentes, 66\%, afirma que não conhecem a Educação 4.0, no entanto, quando indagados sobre o uso de ferramentas digitais, $79 \%$ dos docentes entrevistados afirmam que as utilizavam em suas aulas, antes mesmo da pandemia, de acordo com a Figura 2. Quando indagados sobre o grau de conhecimento sobre tecnologias digitais, $62,3 \%$ consideram que tem um bom grau de conhecimento.

Você conhece a educação 4.0?

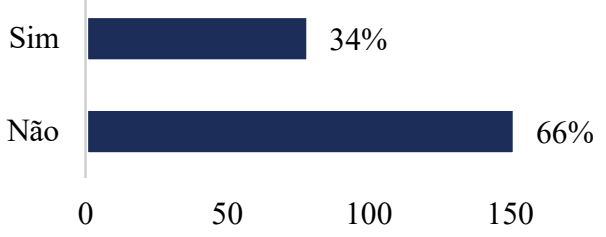

\section{Utilização das TDICs pré REE}

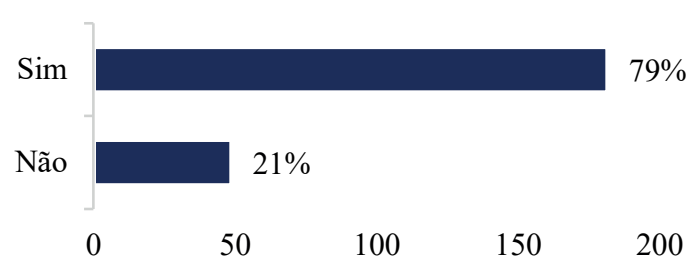

Figura 2 - Conhecimento sobre educação 4.0 e utilização de ferramentas digitais.

De acordo com Anjos, F. R. et al. (2010) para haver uma melhor utilização dos recursos tecnológicos como mediadores da aprendizagem, é preciso que haja formação para que o professor conheça as tecnologias e todas as suas possibilidades educacionais. A Secretaria da Educação da Ciência e da Tecnologia do Estado da Paraíba, promoveu uma formação voltada para a utilização de ferramentas tecnológicas, voltada para a utilização do Google Sala de Aula, ferramentas de avaliação, de produção de vídeos e etc., antes do início do REE. Dos entrevistados, $82 \%$ participaram, e $62 \%$ destes, afirmam que a formação foi satisfatória ou ótima.

Corroborando com Macêdo et al. (2014) e Carvalho et al. (2018) busca-se compreender como o ambiente escolar tem colaborado e dado condições para que a educação acompanhe a atual e constante evolução tecnológica sob a perspectiva da Educação 4.0, a qual é baseada principalmente nas metodologias ativas: STEAM, a cultura Maker, o ensino híbrido, a aprendizagem baseada em projetos e etc. Os docentes foram questionados sobre os recursos para o desenvolvimento de tais metodologias. Observa-se que $35 \%$ dos professores não tem disponível laboratório de informática e $52 \%$ dos professores não tem laboratório da disciplina que leciona disponível. Dos $48 \%$ que tem laboratório disponível para trabalhar a disciplina que leciona, 78\% classificam o laboratório entre péssimo, ruim ou regular, como mostrado na Figura 3.

Laboratórios da disciplina

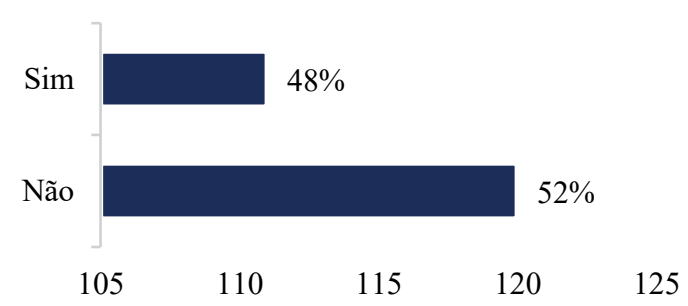

\section{Classificação do laboratório}

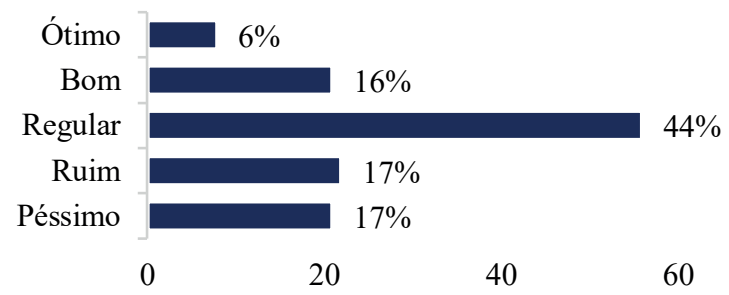

Figura 3 - Existência e classificação dos laboratórios da disciplina.

Em 2017 o Governo do Estado da Paraíba, implementou a tecnologia 3D nas escolas estaduais. Com o investimento feito pelo estado da Paraíba é possível imprimir objetos tridimensionais. O Governo da Paraíba reconheceu o potencial da tecnologia no 
processo educativo, a exemplo de países como China, EUA e Reino Unido, que estão na vanguarda no que se refere ao uso e inserção da impressora 3D nas escolas. Dos entrevistados, $15 \%$ respondeu ter impressora 3D disponível na instituição, no entanto, $63 \%$ destes, respondeu que a tecnologia 3D não é utilizada na escola, de acordo com a Figura 4. A tecnologia 3D, alinhada a área de robótica e automação, tem se mostrado uma ferramenta tecnológica muito utilizada na indústria e quanto à educação, segundo Lemke et al. (2016), a impressão 3D tem se tornado, uma opção acessível para a produção de objetos de aprendizagem em diversas áreas e em vários níveis de ensino. Dessa forma, a tecnologia 3D pode ser uma ótima ferramenta nas metodologias ativas descritas anteriormente.

\section{Utilização da impressora 3D}

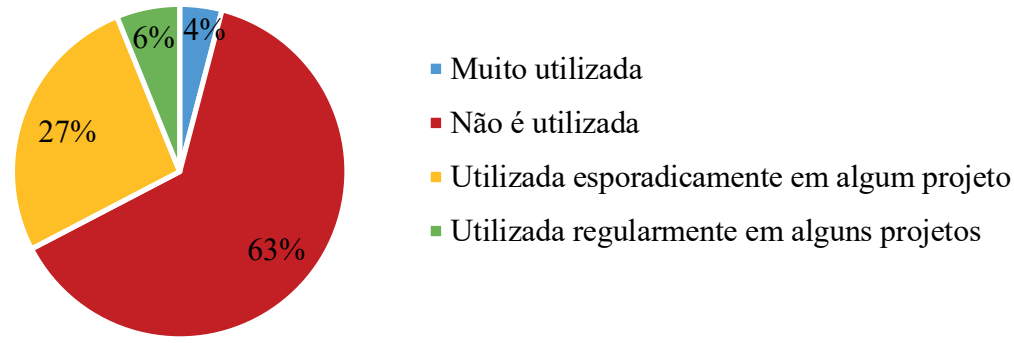

Figura 4 - Utilização da impressora 3D.

Com o intuito de entender como está ocorrendo a inserção das TDICs durante o REE da Paraíba e uma possível evolução tecnológica frente a situação atípica que os docentes estão inseridos, os mesmos foram questionados sobre a utilização das TDICs antes do Regime Especial de Ensino e a inserção de tais ferramentas durante o regime. Dos entrevistados, 79\% responderam que utilizavam TDICs antes do chamado ensino remoto e, $99 \%$ dos professores passaram a utilizar ou a utilizar ainda mais as tecnologias no período de pandemia. Os resultados mostram que em relação ao ensino presencial, o uso do Google Sala de Aula e o Google Meet, subiu 65\% e 80\%, respectivamente, durante o ensino remoto, enquanto que a utilização do Youtube diminuiu 12\% e as redes sociais, caiu 3\% seu uso. Houve também o aumento de outras ferramentas pedagógicas tecnológicas, tais como: Gamificação, pladet, OBS, Jamboard, Sway, Canvas e podcasts. Tais ferramentas, em virtude do REE, têm sido utilizadas através das TDICs, de forma a incentivar, motivar e criar uma maior interação com os estudantes durante as aulas remotas. A diminuição do uso do Youtube leva a acreditar que os professores estão produzindo com maior frequência seu próprio material para vídeo aulas, o que foi identificado também através dos canais de Youtube de algumas escolas.

Os docentes, quando questionados sobre as principais dificuldades em relação a preparação das aulas durante o REE, responderam que a maior dificuldade está em como engajar e avaliar o estudante, $89 \%$, afirma que a participação dos discente no ensino remoto é regular, ruim ou péssima, mostrando-se assim insatisfeitos com o feedback de seus estudantes. A utilização e inserção da tecnologia nas aulas não é a maior dificuldade, mesmo assim, 32\% tem dificuldade nesse quesito, Quando observada a faixa etária, dos que responderam que tem dificuldade em utilizar a tecnologia, observa-se que quanto maior a faixa etária, maior o percentual de dificuldade, de acordo com a figura 5 . 


\section{Dificuldade em TDICs de acordo com a faixa etária}

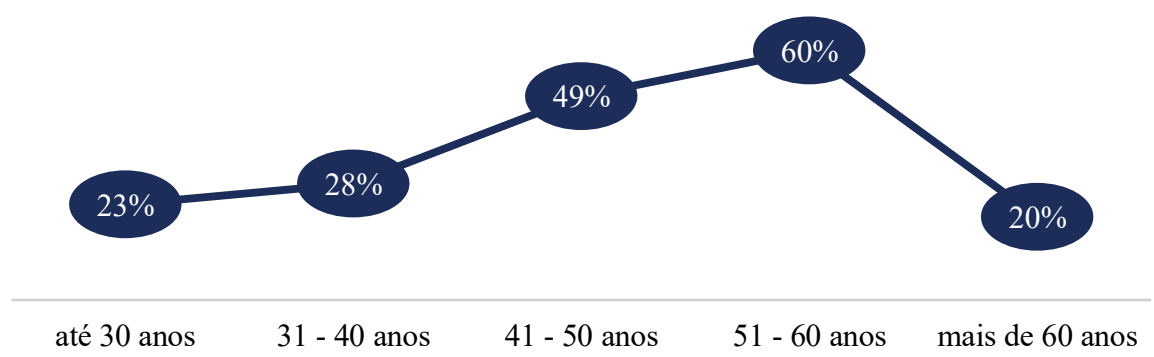

Figura 5 - Dificuldade em TDICs de acordo com a faixa etária.

Observa-se que ocorre uma exceção, para entrevistados com mais de 60 anos, talvez por estes representarem apenas $2 \%$ do total de entrevistados, o que provavelmente decorra da dificuldade em utilizar a tecnologia, tendo em vista que a coleta de dados foi realizada eletronicamente. O maior desafio no ensino presencial em utilizar a tecnologia, de acordo com as respostas dos docentes é a indisponibilidade de equipamentos/material, seguido pela falta de manutenção quando há equipamentos e falta de formação.

\section{Conclusões}

Este trabalho proporcionou um panorama sobre o processo de ensino e aprendizagem em ciências e matemática das escolas estaduais do estado da Paraíba, e como os docentes dessa área tem acompanhado a constante evolução tecnológica que ocorre em todos os âmbitos da atual sociedade.

A partir do estudo do referencial teórico, optou-se por realizar um estudo de caso, a partir de um questionário de coleta de dados on-line em decorrência da atual situação de pandemia da COVID-19. O perfil de docentes alcançado é em sua maior parte de jovens e com tempo de profissão de até 10 anos. Mesmo afirmando que não conhecem a Educação 4.0, é perceptível o quanto os mesmos estão imersos nesse processo educacional. No entanto, ainda enfrentam as antigas e, ainda assim atuais, barreiras no que concerne ao uso de TDICs: indisponibilidade de equipamentos/material, falta de manutenção de equipamentos/material e falta de formação.

Um fator extremamente preocupante é que mais da metade dos entrevistados afirma que a escola não possui laboratório para trabalhar a disciplina que lecionam, e ainda que os laboratórios existentes são considerados pela maioria, péssimos, ruins ou regulares. Nota-se uma real e preocupante subutilização das metodologias ativas, a exemplo da não utilização da tecnologia $3 \mathrm{D}$, quando disponível, a maior parte dessa tecnologia está perdendo-se nas escolas, talvez, justamente pela falta de formação.

O ano de 2020, em virtude da situação de pandemia da COVID-19, teve uma grande influência no processo evolutivo tecnológico no âmbito educacional. Os professores do estado da Paraíba tiveram que se reinventar. O REE trouxe grandes desafios, não apenas para os professores, mas para a gestão, os alunos, os pais. No entanto, é sabido que ao professor foi dada a grande responsabilidade de utilizar as TDICs. Observa-se que $99 \%$ dos professores afirmam utilizar as TDICs devido ao REE. Observase ainda que quanto maior a faixa etária dos professores, maior dificuldade tem-se em utilizar a tecnologia no processo de ensino e aprendizagem.

É possível que o ano de 2020 seja um marco para a evolução da educação 4.0. O apoio da tecnologia durante o chamado ensino remoto, trará consequências futuras em como os professores ministram suas aulas. Talvez se fosse feita a pergunta "Qual a maior 
dificuldade de ensinar no Regime Especial de Ensino?" no início do ano, a resposta majoritária fosse "a utilização e aplicação das tecnologias", hoje, embora ainda seja uma das dificuldades, a maior dificuldade é em como engajar o aluno nas aulas e em como avalia-los. A partir da pesquisa apresentada, é possível observar que seria interessante a realização de novos estudos que contemplassem uma visão mais ampla de como vem sendo a utilização das TDICs, durante o ensino remoto, não só da rede estadual da Paraíba, mas em escolas municipais e particulares do estado; uma visão por parte do aluno, sobre as aulas remotas e como a utilização das TDICs poderia engajar mais esse aluno nas aulas, tanto no ensino remoto, quanto no ensino presencial, o qual não terá mais como voltar ao que foi antes, pois ficará a herança da (r)evolução tecnológica, a qual professores, alunos, gestores e pais carregarão deste ano.

\section{REFERÊNCIAS BIBLIOGRÁFICAS}

ANJOS, F. R. et al. A Percepção de Professores Sobre o Uso das Tecnologias de Informação e de Comunicação - TIC's no processo de Ensino. I Simpósio Regional de Educação/Comunicação, Aracaju, 2010.

BRASIL. Base Nacional Comum Curricular (BNCC). Educação é a Base. Brasília, MEC/CONSED/UNDIME, 2018. Disponível em: http://basenacionalcomum.mec.gov.br/images/bncc_ei_ef_110518_versaofinal_site.pdf. Acesso em: 4 set. 2020.

. Instituto Nacional de Estudos e Pesquisas Educacionais Anísio Teixeira. Censo

Escolar 2019. Brasília, 2019. Disponível em: http://censobasico.inep.gov.br/censobasico/. Acesso em: 12 de set. 2020.

BATTISTI, S. Scheffer, N. F. A utilização de TIC no ensino da matemática em escolas estaduais da cidade de Erechim-RS: um diagnóstico. In: XII ENEM - Anais Encontro Nacional de Educação Matemática, Anais, São Paulo, SP, 2016.

CARVALHO, L. A. et al. Formação de Professores: Implementação de Práticas Inovadoras em Sala de Aula. Pleiade, 12(25): 64-78, Edição Especial VI CIEdu, dezembro, 2018.

CARVALHO NETO, Cassiano Zeferino de. Educação 4.0: INOVAE4. Plataforma de soluções para suporte aos processos da Educação 4.0, [s. 1.], 17 jan. 2018. Disponível em: https://inovae4.com.br/educacao-4-0-entrevista-com-o-professor-cassiano-zeferino-decarvalho-neto-autor/. Acesso em: 16 set. 2020.

DAMASCENO, Marina Sousa Manoel. Uso de Tecnologias Digitais de Informação e Comunicação no Ensino de Ciências e Biologia. Orientadora: Karina Carvalho Mancini. 2019. 142 p. Dissertação (Mestre em Ensino na Educação Básica) UNIVERSIDADE FEDERAL DO ESPÍRITO SANTO, São Mateus, 2019. Disponível em: http://repositorio.ufes.br/bitstream/10/11309/1/tese_13060_105Marina\%20Damasceno.pdf. Acesso em: 18 set. 2020.

FÜHR, Regina Candida. O diluvio digital e seus impactos na educação 4.0 e na indústria 4.0. VI Congresso Ibero-Americano, 2018a. 
FÜHR, Regina. Candida. (Re)apreender a docência no contexto da educação digital. Rev. Educ., Brasília, ano 41, n. 157, p. 92-107, out./dez. 2018 b.

GIASSE, Maristela Gonçalves; RAMOS, Mariana Colombo. Revista Dynamis: Tecnologias da Informação e Comunicação no Ensino e Aprendizagem de Ciências. Revista Dynamis, Blumenau/SC, v. 22, ed. 2, p. 52-62, 2016.

LEMKE, R.; SIPLE, I. Z.; FIGUEIREDO, E. B. OAs para o ensino de cálculo: potencialidades de tecnologias 3D. In: Revista Novas Tecnologias na Educação (RENOTE). CINTED-UFRGS. Porto Alegre, v.14, n.1, julho, 2016.

LOUREIRO, Bruna Cristina Oliveira. O uso das tecnologias da informação e comunicação como recursos didáticos no ensino de física. Revista do Professor de Física, Brasília, v. 3, ed. 2, p. 93-102, Brasília, 2019.

MACÊDO, J. A.; PEDROSO, L. S.; VOELZKE, M. R.; ARAÚJO, M. S. T. Caderno Brasileiro de Ensino de Física,31, 167, 2014.

MELO, Sabrina Salgado De Melissa; OLIVEIRA, Edson A. De Araújo Querido. Educação a Distância: Desafios da modalidade para uma Educação 4.0. Revista Interdisciplinar de Tecnologias e Educação, [S.1.], v. 5, n. 1, p.15, nov. 2019. ISSN 2447-5955. Disponível em: http://rinte.ifsp.edu.br/index.php/RInTE/article/view/473. Acesso em: 04 set. 2020.

MOYSÉS, Gerson Luís Russo; MOORI, Roberto Giro. Coleta de dados para a pesquisa acadêmica: um estudo sobre a elaboração, a validação e a aplicação eletrônica de questionário. XXVII Encontro Nacional de Engenharia de produção: A energia que move a produção: um diálogo sobre integração, projeto e sustentabilidade, Foz do Iguaçu, 2011.

PRODANOV, Cleber Cristiano. FREITAS, Ernani Cesar. Metodologia do Trabalho Científico: Métodos e técnicas da pesquisa e do trabalho acadêmico. $2^{\mathrm{a}}$ edição, Feevale, Novo Hamburgo, 2013.

REIS, R. S.; LEITE, B. S.; LEÃO, M. B. C. Apropriação das Tecnologias da Informação e Comunicação no ensino de ciências: uma revisão sistemática da última década (20072016). Revista Novas Tecnologias na Educação (RENOTE), CINTED-UFRGS. Porto Alegre, v. $15 \mathrm{n}^{\circ}$ 2, 2017.

SANTOS, Leon. Revolução 4.0: Quarta Revolução Industrial já está em vigor e deve mudar a realidade que conhecemos. Revista Brasileira de Administração, [s. 1.], n. 30, ed. 132, p. 22-28, setembro/outubro 2019. Disponível em: https://online.flippingbook.com/view/444900/. Acesso em: 3 set. 2020.

SCHUHMACHER, Vera Rejane Niedersberg; ALVES FILHO, José de Pinho; SCHUHMACHER, Elcio. As barreiras da prática docente no uso das tecnologias de informação e comunicação. Ciênc. educ. (Bauru), Bauru, v. 23, n. 3, p. 563-576, jul. 2017.

TELES, Jhonata. Indústria 4.0: Tudo que você precisa saber sobre a Quarta Revolução Industrial.. Planejamento e Controle de Manutenção DESCOMPLICADO, [s. l.], 31 jul. 2017. Disponível em: https://engeteles.com.br/industria-4-0/. Acesso em: 16 set. 2020. 